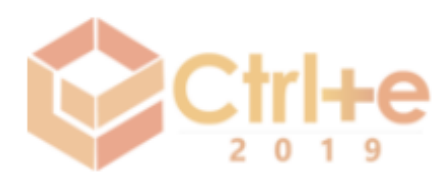

IV Congresso sobre Tecnologias na Educação (Ctrl+E 2019)

Recife, Pernambuco - Brasil

28 a 30 de agosto de 2019

\title{
Role-Playing Games Digitais e Ensino-aprendizagem com Adolescentes em Contexto Escolar: Interfaces Histórico- Culturais e Psicanalíticas
}

Fernando R. de Lima Júnior1, Flávia M. de A. e Peres1, Ladjane de F. R. Caporal3

1Programa de Pós-graduação em Educação, Culturas e Identidades - Universidade Federal Rural de Pernambuco (UFRPE)

3Departamento de Psicologia - Faculdade de Ciências Humanas de Olinda (FACHO)

feh.nando93@gmail.com, peres.flavia@gmail.com,

ladjane.caporal@gmail.com

\begin{abstract}
It is a literature review, with dialectical foundations between historical-cultural psychology and psychoanalysis, with the purpose of reflecting the potential of digital role-playing games (RPGs) as a teachinglearning tool with adolescents in a school context. It is based on a sociointeractionist conception of education, based on Vygotskian postulates and Lacanian psychoanalysis, in order to: expose the origins and playability of RPGs, also in their digital condition, and defend the use of these games as pedagogical instruments that allow internalization (Vygotsky) of school contents, considering the identification (Lacan) engendered by desire in the construction of such contents.
\end{abstract}

Resumo. Apresenta-se revisão de literatura, com fundamentos dialéticos entre a psicologia histórico-cultural e a psicanálise, com o objetivo de refletir a potencialidade dos Role-playing games (RPG) digitais como instrumento de ensino-aprendizagem com adolescentes em contexto escolar. Embasa-se em uma concepção sociointeracionista de educação, pensada a partir dos postulados vygotskyanos e da psicanálise, para: expor as origens $e$ a jogabilidade dos RPG, também em sua condição digital, e defender a utilização desses jogos como instrumentos pedagógicos que permitem a internalização (Vygotsky) de conteúdos escolares, considerando a identificação (Lacan) engendrada pelo desejo na construção de tais conteúdos.

\section{Introdução}

No curso da vida, a imaginação emerge como aspecto fundamental do humano. Ela atravessa suas histórias e a construção de personagens com os quais vem a identificarse, ou até mesmo a opor-se. Trata-se de uma imaginação que não se opõe à realidade, mas que faz parte de seu processo de humanização, sendo elemento fundante na interiorização que permite a constituição das funções psicológicas superiores, como teorizará Vygotsky, e da formação do próprio inconsciente, como fundamenta a psicanálise. Diferentemente dos animais, que encontram na brincadeira uma forma instintiva de organizarem sua operação biológica na natureza, os humanos, seres de 
cultura, destituídos do instinto natural, encontram no ato do jogo possibilidades simbólicas e lúdicas de se fazerem constituir sujeitos e assim serem reconhecidos no laço social. As expressões sociais humanas, perpassando a arte, a religião e a guerra, umas com maior teor de evidência, outras menos, apresentam relações com o jogo, bem como com as regras e a imaginação que o circunscreve [Huizinga 2012].

Convém sinalizar breve compreensão do que seria a adolescência. Concepção contemporânea, que, na psicologia histórico-cultural e na psicanálise, diz respeito ao tempo subjetivo, caro à vida psíquica das sociedades industrializadas, que permite ao humano a consolidação e o reforçamento de laços sociais envolvendo os afetos conturbados frente à passagem do familiar ao estranho - corporal e social. Frente aos desafios dessa passagem, as expressões da cultura podem amparar simbolicamente o adolescente em suas (res)significações e em seu posicionamento subjetivo frente ao laço social contemporâneo. Essas expressões seriam: "a música, o esporte, a dança, as mídias digitais, o teatro, entre outras, [que] possibilitam ao adolescente passar pelo processo pubertário e pelos desafios subjetivos" [Brasil et al. 2015], implicando as próprias formações simbólico-subjetivas da puberdade, particulares do adolescer.

A essas expressões culturais, Melo [2014] acrescenta a própria educação e a produção científica que, por seus discursos, tanto podem amparar o adolescente, quanto os destituir de sua posição de sujeito, acarretando-lhes ainda mais instabilidade psíquica e angústia. Frente a estas situações discursivas que por consideráveis vezes destituem o adolescente de sua autonomia frente ao seu desejo, o jogo digital pode valer como suplência a este desejo de "fazer parte da história" onde pode fazer laço, "influenciandoa", inclusive. Isso, porque nessa configuração de jogo "o indivíduo sai do lugar de apenas leitor para o lugar de protagonista que emerge no universo da narrativa, e tem interesse de imergir e interagir com ela" [Mendes e Silva 2017]. Algo muito próximo ao que o adolescente está passando em seu tempo subjetivo. Evidentemente que tal suplência não deve ser entendida como finalidade, mas como um recurso considerável ao campo educativo de modo a aproximar, frente aos processos de destituição subjetiva do sujeito no espaço social, o adolescente de seu desejo e, de forma menos angustiante, lidar com as interfaces culturais entre educação escolar e configuração social.

Com base no levantamento bibliográfico, defende-se que as tecnologias digitais, especialmente os jogos, e, neste estudo, os Role-playing games (RPG) digitais ou Massively Multiplayer Online Role-Playing Game (MMORPG), podem contribuir com processos institucionalizados de ensino-aprendizagem para a construção de significados e sentidos entre os sujeitos do processo, no curso dos objetivos das aulas. Com isso, compreende-se os RPG digitais como ferramentas processuais do aprendizado, não seu fim. Este artigo é fruto da pesquisa de mestrado, ainda em curso, de seu autor principal com a iminência do início da fase de campo, cuja pesquisa bibliográfica foi fundamental para a configuração de uma arguição defensiva frente ao uso dos RPG digitais como instrumento pedagógico. Os autores aqui referenciados tiveram suas produções levantadas para este estudo através da Biblioteca Digital Brasileira de Teses e Dissertações, das bases online Scielo e Pepsic, no período de 2014 a 2018, com a utilização dos seguintes indicadores: Role-playing games digitais, ensino-aprendizagem, adolescência, psicologia histórico-cultural, internalização, Vygotsky, psicanálise, Lacan, identificação. Também se recorreu a outras obras da literatura científica que, mesmo não estando circunscritas a esta faixa temporal, trouxeram contribuições significativas ao objeto cujo estudo está em curso. 
No tocante à construção dialética entre a psicologia histórico-cultural e a psicanálise, este trabalho identifica nelas possibilidades de interlocução consideráveis frente ao seu objeto. Em que, ressalvando suas respectivas particularidades e concepções de sujeito e mundo, podem dialogar frente ao entendimento de um sujeito cognitivo-consciente, que apreende e internaliza os objetos do mundo, inclusive os conhecimentos que nele estão circunscritos, a partir da mediação simbólica e interativa de outros sociais - como postula a escola de Vygotsky -, e de um sujeito do inconsciente, que se constitui mediante as relações e os vínculos com aqueles outros de sua espécie que podem lhe transmitir a condição humana a partir dos laços identificatórios - como arguirá a psicanálise. Com isso, não se reflete sobre a construção de uma outra tese de sujeito (supostamente tentando articular estas de Vygotsky e Lacan), mas de se pensar as possibilidades de interseção que estas epistemologias permitem ao refletir a educação, a aprendizagem, a adolescência e o uso das tecnologias digitais, especialmente os jogos, nesta área de estudo e pesquisa. Este artigo apresenta uma possibilidade de interpretar o ensino-aprendizagem, mediado pela interface digital, a partir do(s) (des)encontro(s) entre essas teorias. Uma que pensa a própria relação filo e ontogenética da aprendizagem e da condição, fundamentalmente cultural, do humano (psicologia histórico-cultural); e outra que busca entender, também nos limiares da filo e ontogênese, a constituição desejante do humano em sua dimensão inconsciente (psicanálise).

\section{RPG: origens e jobabilidade}

O RPG, como jogo de interpretação de personagens, pode ser compreendido como uma game que permite a criação e a vivência de histórias ficcionais [Melo 2014]. Melo [2014] informa que esses jogos surgiram na década de 70 do século XX, com o lançamento de Dungeons \& Dragons (D\&D), em 1974, e de Empire of Petal Throne, em 1975. Estes jogos foram lançados nos Estados Unidos da América e espalharam-se pelo mundo, à medida que os jogadores se iniciavam em sua prática [Melo 2014; Corrêa 2017]. Envolvem temáticas medievais e surgiram diante da inspiração das obras literárias de Tolkien: O Hobbit, em 1937; O Senhor dos Anéis, em 1954; O Silmarillion, em 1977. Não houve contentamento em apenas ler estas histórias da "Terra Média", foi necessário se criar algo para deste mundo, ainda que virtualmente, fazer parte e assim protagonizar os atos que o envolvem [Melo 2014; Corrêa 2017].

No jogo de mesa, a jogabilidade baseia-se em tabuleiros, estatísticas e dados, assumindo uma infinidade de possibilidades imaginativas. Corrêa [2017] diferencia os jogos RPG dos jogos de tabuleiro e estratégias convencionais, argumentando que: "as grandes diferenças do D\&D para esses jogos de estratégia são os fatos de que em sua composição, sentados em volta de uma mesa, usando livros de regras, papel, lápis e um conjunto de dados de múltiplas faces, cada jogador deve representar um personagem e não um exército; e também a existência de um jogador especial denominado Dungeon Master - "mestre" do jogo, que mais tarde passaria a se chamar também narrador - cujo papel é, ao mesmo tempo, propor um desafio, uma aventura, aos demais jogadores e também ser o responsável pela condução da narrativa, descrição do cenário e interpretação de qualquer outro personagem da história que não seja de um jogador - os chamados non-player character (NPCs), muitas vezes antagonistas dos personagens de jogadores. Ao longo da narrativa, os gamers devem tomar as decisões de seus personagens - que no plano da imaginação realizariam as ações propostas, tendo o 
sucesso ou o fracasso em suas tentativas baseado na aleatoriedade representada pelo rolar de dados. Conforme os jogadores tomam suas decisões, realizam ações ou enunciam suas falas, os dados rolam e o mestre-narrador descreve os resultados e as reações do cenário, constituindo, portanto, uma espécie de narrativa interativa e colaborativa, cercada pelo improviso e por uma enorme liberdade criativa".

Note-se que tal jogabilidade é amplamente atravessada por questões subjetivas que tocam a consciência-cognitiva de seus jogadores e os conteúdos de seus respectivos inconscientes, numa configuração longe de ser dicotômica, mas em consideração à complexidade que engendra o humano a partir destas dimensões. As escolhas dos personagens e aquelas próprias que se voltam para as ações no curso da narrativa dizem muito dos conteúdos subjetivos, da personalidade, dos traços identificatórios e de como certos conhecimentos da cultura estão sendo apreendidos e internalizados por estes sujeitos que neste espaço se põem a jogar. Os RPG chegaram ao Brasil no final da década de 1980. Sua vivência ganhou eco significativo entre jovens universitários e adolescentes, que já jogavam com as versões importadas, em língua inglesa, dos livros que instruíam a prática do jogo [Melo 2014; Corrêa 2017]. A modalidade dos MMORPG permitiu aos jogadores a vivência do RPG através do aparato tecnológico do computador ou de um console, vivenciando a narrativa através dos recursos midiáticos da imagem de do som, bem como da manipulação dos controles do game. A importância do jogo não consiste no cumprimento de uma finalidade, haja vista vastidão de possibilidades que a narrativa pode cursar; há vários objetivos e uma infinidade de missões em cena, que podem ser dadas aos jogadores para cumprirem individualmente (missões solo) ou em campanha (com um grupo de aventureiros). Essa configuração permite aos jogadores a construção da "capacidade de posicionamento e resiliência" [Melo 2014], grandes exercícios de maturidade, os quais se esperam do adolescente em sua transitoriedade da infância à vida adulta. Os RPG são jogos cooperativos, mesmo quando jogados individualmente, pois o jogador precisa cooperar com as demais personagens para conseguir os objetivos das missões apresentadas pela narrativa [Francisco 2014].

Nos MMORPG, a função do mestre se dilui através do cenário virtual computadorizado, quer com uma narrativa linear a ser seguida, quer com várias possibilidades transcursivas à história principal de um game, permitindo ao jogador cumprir várias missões e imergir por horas a fio na realidade virtual, que lhe oferece cenários fantásticos, sob temáticas medievais ou futurísticas, construindo e destruindo impérios, inventando personagens ou interagindo com outros, tudo a um clicar do mouse ou movimento do joystick. Existirão regras com o intuito de dar coerência ao universo, à narrativa e as ações no qual a história do jogo acontece [Marins 2017]. As personagens são construídas pelos jogadores, individualmente, a partir dos atributos que elegerem. Os jogadores escolhem os pontos fortes e fracos, a espécie a que seu personagem pertencerá, a classe, os atributos mais físicos, inclusive os emocionais. Essas personagens não são unidimensionais, muito menos simplistas [Marins 2017]. Na função de avatares, humanos, parahumanos ou animais, o jogador representa a si e seu desejo no mundo virtual.

Nisto já se vislumbra a interlocução da concepção de sujeito cognitivoconsciente (Vygotsky) e do sujeito do inconsciente (Lacan): na personificação e interpretação de personagens, ao passo que o sujeito traz à tona elementos que expressam sua apreensão consciente do mundo - os objetos da cultura que faz uso para 
dar corpo a seu personagem, os conteúdos e conhecimentos que precisa se valer para assim constituí-los -, também evoca os elementos identificatórios que perpassam sua vida psíquica inconsciente, retomando e projetando na cena digital os traços que o constituíram na infância, tendo a oportunidade de ali, na interface digital, poder (re)pensá-los e atribuir-lhes (novos) significados - ou seja: as escolhas dos atributos, ainda que fantasiosos, das personagens, nunca serão ao acaso, haverá nestas escolhas aspectos inconscientes, da ordem do desejo, que rememoram ou retomam e podem permitir uma elaboração dos conteúdos que no jogo são projetados. Os RPG, situam-se "entre as fronteiras do real e do irreal, onde há acontecimentos impossíveis de serem explicados por leis que regem o mundo fora da narrativa" [Gregório 2014]. Há uma ruptura, consideravelmente influenciada pelos tempos da pós-modernidade, entre a concepção do que se configurava como racional e lógico. Surge o fantástico que leva ao jogador de RPG e/ou MMORPG, para "além do que há de concreto, podendo as histórias flutuarem em um espaço [supostamente] ilógico" [Gregório 2014]. Esses jogos colocam seus jogadores em um mundo que rompe com os paradigmas do que lhes é familiar. Coloca-os em "uma complexa interação com este universo novo" [Gregório 2014]. Há uma proximidade com a adolescência como tempo de passagem do familiar ao estranho social, pois é possível que os jovens encontrem nos jogos amparo e sentido para atenuar a angústia que esta passagem lhes acarreta. Trata-se de um apelo ao simbólico mediado pelo virtual e nele projetado.

O jogo permite aos jogadores uma simulação da vida [Corrêa 2017]. "Ao jogar, o indivíduo adquire habilidades que o fazem imergir no jogo ao tempo que aprimora outras já existentes" [Mendes e Silva 2017]. Por sua ficção, possibilita que os jogadores explorem criando e criem explorando resoluções de problemas através da imaginação e fazendo uso de um tanto de ousadia sem que isso represente um risco iminente. Através da interatividade, participando de forma ativa, o gamer age, reage e intervém no processo narrativo do jogo: ao passo que é receptor de uma dada informação, da mesma também é emissor [Antonio Júnior 2014]. Sobre a virtualidade, em função dos avanços tecnológicos que possibilitam programadores construírem realidades fantásticas a serem ofertadas aos jogadores, a condição virtual assume um sentido inovador.

\section{RPG e ensino-aprendizagem com adolescentes}

\subsection{A adolescência e o espaço virtual dos games}

Freud [2006] ensinou que a tarefa mais árdua para o adolescente é desapegar-se da autoridade de seus pais, algo que para Lacadée [2012] será uma atividade na qual a fantasia exercerá tarefa importante. Nesse sentido, "a atividade fantasmática toma como tarefa livrar-se dos pais, que de agora em diante são desdenhados, seja sob o modo de sonhos diurnos, de leituras, de escrituras de diários íntimos ou de jogos diversos" [Lacadée 2012]. Com isso, Kelles e Lima [2017] explicam que "para alguns sujeitos a tela do celular ou do computador pode funcionar como uma moldura para as fantasias adolescentes. [...] nos jogos eles podem ser o que quiserem, é um espaço para a livre experimentação". Para Lima [2009], "o ciberespaço se configura como um novo espaço público, onde o jovem se sente 'incluído'. Um espaço onde é possível encontrar os seus pares e exercitar a passagem do privado ao público, da família para o laço social mais amplo". Dessa forma, o sujeito pode se sentir pertencente a rede, agir nela, significá-la. Essa autora ainda ressalta que na interação social através do ciberespaço há possibilidades identificatórias, ainda que sejam, em sua maioria, imaginárias [Lima 
2009]. Os sujeitos na contemporaneidade estão indo além de limites entendidos como humanos [Gregório [2014], nessa condição pós-humanista, reflete-se acerca deste "estágio da humanidade tecnológica cuja principal meta é a transcendência das limitações físicas e biológicas do humano. Esse desejo de ultrapassagem dos limites ou fronteiras [...] encontra sua realização máxima no abandono da prisão corporal" [Felinto 2006], que vem encontrando certo sucesso frente às experiências de imersão proporcionadas pelo mundo virtual. Entre as quais está a ofertada pelos jogos RPG digitais.

O jogo oferece ao sujeito, especialmente ao adolescente, um meio pelo qual possa sair do mundo de insegurança e adentrar em um universo que pode controlar, reger, não morrer, pois sempre que o game over surgir, outra chance de recomeçar será dada. No mundo virtual dos MMORPG é possível ao sujeito arriscar-se e nisto obter prazer [Francisco 2014]. Nesse sentido, assume um lugar histórico de significação e construção de sentidos e que, se sustentado pela ordem simbólica da alteridade, da relação com o Outro social, pode se tornar um instrumento cultural válido de aprendizagem em que se é possível arriscar, errar e repetir até alcançar o êxito. Uma movimentação importante de ser reconhecida tanto em seu caráter psíquico de repetição e elaboração, quanto em seu caráter educativo de transformação.

\subsection{Ensino-aprendizagem, educação e o jogo como instrumento pedagógico}

O foco do ensino-aprendizagem consiste em preparar estudantes para viverem com os seus semelhantes em sociedade [Mrech 2003]. Com isso, distancia-se de uma concepção tradicional de educação, uma vez que essa apreende os sujeitos estudantes, por vezes, de forma estática e inalterável em função de seu tempo e espaço sociais [Mrech 2003]. Preconiza-se que o ensino-aprendizagem, como processo educativo, é engendrado por seu tempo histórico no laço cultural. Como explica Mrech [2003], Lacan e Vygotsky criticaram a forma a-histórica de compreender os sujeitos envolvidos na cena educativa, e posicionaram-se em favor da compreensão desses sujeitos a partir de sua história filogenética e ontogenética através dos laços que a cultura pode ofertar-lhes. Este processo pode permitir ao estudante, através das relações, a construção de habilidades e conhecimentos para agir de forma autônoma, reflexiva, crítica e ética sobre o mundo, pensando sobre si e sobre os outros, cooperando, desenvolvendo formas interdisciplinares de raciocínio, pesquisando, questionando, criando e inovando.

A educação, em seus paradigmas modernos, não dá mais conta das transformações culturais e sociais que os abalos epistemológicos da pós-modernidade proporcionaram. Vivencia-se um tempo de crise epistemológica e filosófica, de ruptura do paradigma que, pretensiosamente, declarava a existência de um conhecimento objetivo, imutável, plenamente explicado e percebido através de uma lógica positivista. É necessário transformar as metodologias tradicionais "para que o ensino escolar acompanhe as mudanças que ocorrem na sociedade atual" [Marins 2017]. Evidentemente que essa transformação da escola não se restringe à incorporação de novas tecnologias no ambiente escolar, pois é possível que se encontre uma escola amplamente incrementada por artefatos tecnológicos, contudo arraigada no modelo oratório de ensino, que aparece como a transmissão de um saber pronto e acabado, onde o sujeito não se acha implicado" [Mrech 2003]. Isso diverge do paradigma sociointeracionista de Vygotsky, que não dissocia ensino de aprendizagem, compreendendo o processo como um todo: de ensino-aprendizagem, marcando o caráter interativo e mediador ancorado na instância simbólica da relação com o outro social. 
Também dos postulados de Lacan, para quem é impossível o ensino se o sujeito não colocar algo particular nesta construção [Mrech 2003]. Nessa busca por transformação metodológica, os RPG podem exercer um importante papel "por serem excelentes estimuladores para despertar a curiosidade e a criatividade" [Ferreira 2016] dos estudantes, bem como um ótimo recurso para o docente exercer sua função de mediação, demarcando o caráter relacional que envolve a prática dos jogos.

Todo jogo possui uma situação-problema que pode vir a ser solucionada, ou não, pelo sujeito que deve obedecer a um sistema de regras que limitam sua ação no desenrolar do jogo [Ferreira 2016]. Nos RPG isso fica ainda mais complexo, pois por terem várias possibilidades e missões com diversas situações-problema, o jogador, cooperativamente, necessita resolvê-las, exigindo dele conhecimentos que atravessam domínios filosóficos, históricos, lógico-matemáticos, linguísticos, políticos, religiosos, e tantos outros que se configuram conforme as especificidades de cada interface. Vygotsky, já em seus estudos sobre o desenvolvimento infantil, ressalta a função do brincar, ou do jogar, para a aprendizagem do sujeito [Ferreira 2016]. Esta atividade atua na Zona de Desenvolvimento Proximal (ZDP), permitindo àquela pessoa que está na função de mediação (o docente, na escola, por exemplo) a compreensão de como o estudante (criança, adolescente ou adulto, com as devidas diferenças em relação as operações simbólicas possibilitadas pelas funções psicológicas superiores condizentes a cada tempo do desenvolvimento) está internalizando um dado conhecimento e assim o transformando em algo particular, próprio. A ZDP justamente possibilita a compreensão daquelas funções que ainda não amadureceram, ou conhecimentos que ainda não foram bem internalizados, mas que se encontram no sujeito em potencialidade, configurandose como um espaço simbólico intersubjetivo. A escola, em considerações vygotskyanas, tem a responsabilidade institucional do ensino sistematizado e científico, que, por sua vez, repercute sobre o próprio desenvolvimento humano. É, nesse sentido, fundamental que se reconheça este papel importante do espaço escolar comprometido com "o avanço da sociedade como um todo, pois é na e pela apropriação dos conteúdos aí veiculados que o homem se constitui enquanto sujeito consciente, crítico, agente da história" [Ferreira 2016]. É muito válido quando o ensino, ao invés de supostamente vivenciado por um discurso de um sujeito que acredita deter o conhecimento a um ser que, nestes termos, ainda não o detém, são construídas de forma relacional através de uma mediação que não se refere apenas à relação professor-estudante, mas entre pares, estudante-estudante. $\mathrm{O}$ processo de ensino-aprendizagem é interativo e preconiza a colaboração mediadora entre professor-estudante e entre pares (estudante-estudante). Pela colaboração, as experiências (de conhecimento, de vida, de posicionamentos individuais) podem ser elaboradas e produzir resultados ricos desse processo [Marins 2017]. É, por este embasamento, que Vygotsky inova com o conceito de ZDP, como ferramenta processual, que permite ao psicólogo ou educador avaliar o momento do desenvolvimento e do aprendizado em que se encontra o estudante. Algo que não deve apenas considerar aquilo que já fora alcançado ou desenvolvido (nível real), mas, na atenção ao processo que está em curso, atentar para aquilo que está em potencial, que se aposta que o sujeito venha a alcançar (nível potencial). No hiato entre o nível real e o nível potencial encontra-se a ZDP [Vygotsky 2007]. Esta, relacionada aos processos de ensino-aprendizagem, repercute sobre o desenvolvimento.

Na perspectiva psicanalítica, a educação e a subjetivação do humano encontrarão na linguagem a sua possibilidade. Afirma-se que na transmissão de um saber, "reedita- 
se o processo inaugural de nascimento do sujeito, do qual participa sempre um outro/educador, com sua fantasia inconsciente e seu modo singular de desejar" [Coutinho e Carneiro 2016]. Transmissão esta que não está simplesmente relacionada à passagem do conhecimento de uma pessoa que pensa que o detém a outra que supostamente acha que não o tem. A transmissão, na psicanálise, assume sentido "vinculado à instauração de uma verdadeira transferência de trabalho" [Mrech 2003], esta que, por sua vez, leva "o sujeito a investir libidinalmente, a conseguir criar, a conseguir trabalhar, a ler, a escrever, etc." [Mrech 2003] na relação com o outro/educador/par. Nota-se, atualmente, um movimento discursivo, engendrado pela cultura neoliberal e consumista, que enaltece procedimentos educativos tecnicistas, condenando estudantes e educadores a um enquadramento normativo de ensinoaprendizagem que exclui a imprevisibilidade e a singularidade que demarcam o processo de educar. Nesse sentido, há um esvaziamento das possibilidades de "encontros/confrontos entre o adolescer e o educador, de modo que o caminho em direção a uma travessia da adolescência complica-se na mesma proporção que a tarefa de pais e professores diante dos adolescentes" [Coutinho 2015]. A escola, a partir das relações que aí se constituem, exerce influência considerável na passagem adolescente. Relações que podem mitigar, dificultar ou favorecer simbolicamente a transitoriedade que demarca a adolescência, influenciando as próprias escolhas subjetivas que serão engendradas nesta passagem ao laço social. Por isso é importante que, na escola, adolescentes encontrem abertura para exercitarem suas relações, construindo significações para o próprio conhecimento científico que nela deve ser construído, mas não se restringido, ou tendo sua formação subjetiva constrangida, à aquisição de conhecimentos acadêmicos. Nesse ensejo, o uso de jogos digitais pode ser instrumento válido para tais construções.

\section{A potencialidade pedagógica dos RPG digitais: ensaios conclusivos de uma pesquisa em curso}

Haja vista a não conclusão deste estudo, entrementes as fortes considerações reflexivas apontadas pelo referencial exposto, ensaia-se possíveis conclusões que encontraram na revisão de literatura uma defesa considerável em relação ao uso dos RPG digitais como instrumentos de ensino-aprendizagem, considerando as implicações do sujeito cognitivo-consciente e do sujeito do inconsciente que neste campo podem se encontrar. Os RPG digitais como instrumentos pedagógicos permitem ao estudante e ao professor uma forma diferenciada de ensino-aprendizado através de vivências e personificações de narrativas virtuais. Trata-se de uma vivência lúdica da aprendizagem, através da qual se pode experienciar, não apenas os conteúdos programáticos do currículo escolar, mas as relações que envolvem esse contexto, permitindo, inclusive, discussões válidas e, por que não, divertidas de temáticas existenciais e educativo-transversais próprias do adolescer. Apesar de serem ofertados por e inseridos em uma, como a maioria dos instrumentos da cultura pós-moderna, sociedade de consumo, com fundamentos cada vez mais neoliberais, pode-se, através do simbólico que sustenta tais instrumentos, "fisgá-los" em uma outra (res)significação. Estes jogos, frutos do progresso tecnológico da pós-modernidade, podem assumir um sentido de formação crítico-reflexiva e de transformação, atingindo o âmbito da educação. De forma a permitir, sob o amparo da palavra simbólica do Outro social, que jovens possam aproximar-se de seus desejos e terem uma suplência do desamparo social, que se configura na atualidade, através do recurso virtual, mas sem desprenderem-se das relações de alteridade. E tudo isso, 
aprendendo e convivendo [Antonio Júnior 2014; Marins 2017]. Os jogos digitais “integrados por eventos rápidos, móveis e simultâneos, demandam coordenação de variáveis interagentes e, para tanto, habilidades de representação espacial dinâmica e atenção visual distribuída [...]. Com um contexto de aprendizagem, a prática de jogos, [...] com o diferencial das inovações de suporte logístico - o programa, a interface interativa, os joysticks, e mesmo as tecnologias e recursos para interatividade imersiva, apresentam-se como possibilidades na elaboração de habilidades de planejar, prever, reelaborar, analisar o erro, de gerar e avaliar hipóteses, contribuindo para flexibilidade cognitiva e criatividade [Antonio Júnior 2014]. Dessa forma os estudantes podem, divertidamente, ao passo que aprendem, sobre os jogos e os conteúdos pedagógicos que neles estão inseridos, criar algo que lhes seja singular, próprio [Marins 2017]. Algo bastante considerável na passagem adolescente, em que o sujeito se constitui subjetivamente a partir de uma posição singular. Pelos jogos, os laços da transmissão e as relações de mediação que possibilitam o ensino-aprendizagem podem ser alcançados, mas, apenas, se configurados na relação de alteridade com os pares e com aquele que ocupa o lugar da transmissão - para a psicanálise - ou da mediação - para a psicologia histórico-cultural.

Os estudos acerca do uso dos RPG no cenário educacional têm demonstrado o potencial desta ferramenta, que proporciona aprendizagem de forma ativa $\mathrm{e}$ significativa, rompendo com os paradigmas de uma educação tradicional, inócua e ineficiente para os tempos atuais [Marins 2017]. O ensino-aprendizagem, a partir dos RPG, fundamenta "o aprender a ser, a viver, a aprender e a conhecer [...] a fim de problematizar e conectar vida e contexto dos estudantes, alimentando nestes a pulsão que se desprende do pensamento [...] morto" [Melo 2014], inócuo, vazio. Pela vivência dos RPG em sala de aula, como instrumento pedagógico busca-se construir um espaço de aprendizado que permita aos estudantes exporem saberes prévios, ao passo que, no fluxo das narrativas e nas tentativas de resolução das situações-problema que emergirem da partida, possam demandar o interesse pela pesquisa e pela interlocução com seus pares e com o docente [Corrêa 2017]. Justamente uma aposta na compreensão da ZDP que aí se configura e permite ao professor-mediador intervir na construção dos conhecimentos que ali se encontram envolvidos. Como afirma Corrêa [2017], "pensar o jogo associado à educação requer perceber que o próprio jogo é aprendizado". Um instrumento que medeia, sem a pretensão de um fim, uma vez que o processo de ensinoaprendizagem consiste na própria mediação, ao que concerne a própria compreensão das possibilidades interventivas que a ZDP permite ao educador. É importante a reflexão de que a introdução de novas tecnologias de nada vale à transformação da educação se os seus profissionais, amparados pelo sistema de ensino, atravessando, inclusive a formação acadêmica, não se prepararem para compreenderem a sua função e utilizá-los nas salas de aula junto aos estudantes, de forma ativa e colaborativa, (re)construindo conhecimentos. "A tecnologia por si só não basta, independente das virtudes que o recurso tecnológico possa oferecer, o trabalho do professor é indispensável e de extrema importância na promoção de interações sociais" [Marins 2017]. Não há educação, tampouco vida social, sem o laço simbólico da alteridade, destituída esta, só resta a barbárie. 


\section{Referências}

Antonio Júnior, W. (2014). "Jogos digitais e a mediação do conhecimento na perspectiva da psicologia histórico-cultural”. Dissertação - USP, São Paulo.

Brasil, K. C. T. R. et al. (2015). "Adolescência, violência e objetos culturais”, In: Estilos da Clínica, São Paulo, v. 20, n. 2, p. 205-225.

Corrêa, A. L. C. (2017). "Rolando dados, criando histórias, aprendendo História". Dissertação - UFRGS, Porto Alegre.

Coutinho, L. G. and Carneiro, C. (2016). "Infância, adolescência e mal-estar na escolarização", In: Psicologia Clínica, Rio de Janeiro, v. 28, n. 2, p. 109-130.

Coutinho, L. G. (2015). "O adolescente e a educação no contemporâneo", In: Cadernos de Psicanálise, Rio de Janeiro, v. 37, n. 33, p. 155-174.

Felinto, E. (2006). "O pós-humano incipiente", In: INTERCOM: Revista Brasileira de Ciências da Comunicação, São Paulo, v. 29, n. 2, p. 103-118.

Ferreira, M. V. M. de A. (2016). “O RPG e a leitura”. Dissertação - UFCG, Cajazeiras.

Francisco, S. P. (2014). “Cibercultura, jogos e aprendizado textual”. Tese - PUC, SP.

Freud, S. (2006). "Três ensaios sobre a teoria da sexualidade infantil", In: Obras Completas. Vol. VII. Rio de Janeiro: Imago.

Gregório, G. de S. (2014). "Do avatar ao sujeito”. Dissertação - UNB, Brasília.

Huizinga, J. (2012). "Homo ludens" 7. a ed. São Paulo: Perspectiva.

Kelles, N. F. and LIMA, N. L. (2017). "Adolescentes no ciberespaço", In: Tempo psicanalítico, Rio de Janeiro, v. 49, n. 2, p. 202-233.

Lacadée, P. (2012). “A clínica da língua e do ato nos adolescentes", In: Responsabilidades, v. 1, n. 2, p. 253-268, Belo Horizonte.

Lima, N. L. de. (2009). "A escrita virtual na adolescência”. Tese - UFMG, Belo Horizonte.

Marins, E. S. (2017). "O uso de Role-Playing Games (RPG) no ensino de Ciências". Dissertação - USP, Lorena.

Melo, T. F. T. de. (2014). "O Role playing game (RPG) como estratégia para repensar a prática docente em ciências". Dissertação - UEPB, Campina Grande.

Mendes, D. A. and SILVA, O. S. F. (2017). “A narrativa em jogos digitais". In: Proceedings of the Seminário Jogos Eletrônicos, Educação E Comunicação [online], 12., 2017, Salvador: UNEB. p. 40 - 48. Available from: http://revistas.uneb.br/index.php/ sjec/article/view/3553 [Acessed 28 jan. 2019].

Mrech, L. M. (2003). "Psicanálise e Educação”. São Paulo: Pioneira Thomson Learning.

Vygotsky, L. S. (2007). “A formação social da mente”. São Paulo: Martins Fontes. 